- When providing training for the dental team, a knowledge of the training needs of the potential learning group can help ensure the content and design of the learning event is relevant.

- Use of a training needs analysis can help establish the gaps in skills and knowledge or training needs of the dental team.

- A consideration of the different ways people learn can help in the design of courses for people to learn more effectively.

\title{
Delivery of postgraduate dental education to meet the needs of general dental practice - A case study
}

\author{
P. Cannell ${ }^{1}$
}

\begin{abstract}
In order for dental practices to gain the maximum benefit from an educational opportunity such as a course or workshop, it is important that the training received meets the needs of these practices and is delivered appropriately. This paper provides an account of an educational initiative undertaken within the Eastern deanery in 2003 and 2004, 'Essex Promoting Infection Control' (EPIC), which set out to establish training needs in infection control within general dental practices across Essex and then to design and deliver learning events to meet these needs.
\end{abstract}

On 1 January 2002 the GDC launched their statutory Continuing Professional Development (CPD) scheme 'Lifelong Learning' which for the first time required dentists to undertake and document CPD. ${ }^{1}$ In order for an activity to qualify as verifiable CPD certain requirements have to be carried out by the provider of the activities, including providing course notices that contain concise learning objectives and give a clear outline of the course programme. This is a very positive step forward as it should allow practitioners to make more informed choices about what courses they attend. However, practitioners may be unaware of areas within their practices that would benefit from further training, often preferring to source training in areas that the practice is already competent in. This is an unsatisfactory situation as it can lead to a waste of time and money, both valuable resources to a busy dental practice.

How can a provider of education such as a postgraduate deanery help establish in

\footnotetext{
${ }^{1 *}$ Clinical Governance Tutor, Eastern Deanery, General Dental Practitioner, Chalkwell Dental Practice, 1 Old Leigh Road, Leigh on Sea, Essex, SS9 1LB

*Correspondence to: DrP. Cannell

Email:philcannell@yahoo.co.uk
}

\section{Refereed Paper}

Received 18.11.03; Accepted 29.7.04

doi: 10.1038/sj.bdj.4812209

๑) British Dental Journal 2005; 198: 367-369 what subject areas practices require training and the content that needs to be covered within these subject areas? For instance a course on periodontology could cover many different areas such as the latest treatment modalities, periodontal screening and its practical application, hands on periodontal surgery or how to scale and root plane effectively. In order to provide the most appropriate training in this or any subject area, it would be very useful to first have some idea where the gaps in skills and knowledge within your group of potential learners are and then to design appropriate training to meet these needs.

One way to achieve this is by means of a training needs analysis (TNA). Grace ${ }^{2}$ describes the concept of a training needs analysis and how this may be used within a dental practice to establish areas of training need, so that training activities can be found to fulfil these needs. The EPIC initiative involved carrying out a self administered training needs analysis on infection control within dental practices across Essex to establish what gaps in knowledge and practise existed, and then to design appropriate learning events to help fill these gaps. These workshops were delivered at postgraduate education centres across Essex and subsequently at CDS/PDS training days across the Eastern deanery.

\section{How was the training needs analysis carried} out?

A simple training needs analysis questionnaire covering infection control pro-

11. Have all clinical staff received a full course of Hepatitis B immunisation?

Yes No

12. Have all clinical staff had their levels of Hepatitis B antibody checked?

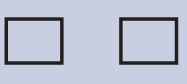

13. Is there a written record of clinical staff immunisation for Hepatitis B held in the practice? 

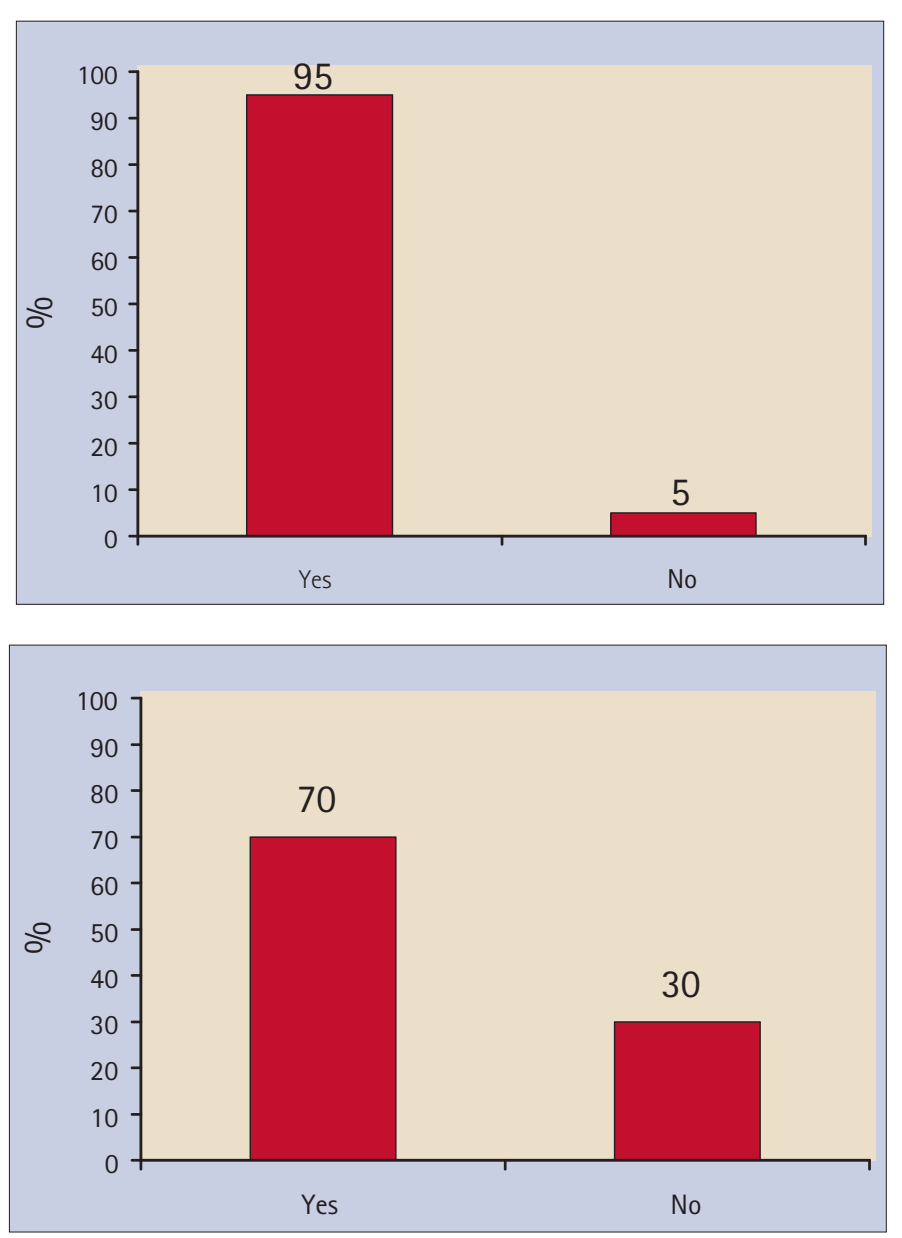

Fig. 2 Results for question 11: 'have all clinical staff received a full course of Hepatitis B immunisation?'

Fig. 3 Results for question 12: 'have all clinical staff had their levels of Hepatitis B antibody checked?' cedures in general dental practice was designed in conjunction with the Essex communicable disease control team, (later to become part of the Health Protection Agency). Figure 1 shows a sample of questions from the questionnaire and illustrates the simple format. The full questionnaire contained 32 questions and also an area where general comments regarding training needs could be made. A pilot survey of eight practices was carried out with particular reference to ease of use and time required to complete the questionnaire.

After minimal modifications the final draft questionnaire was distributed from the Eastern deanery offices to 242 dental practices in Essex, along with a covering letter that explained the initiative and the potential benefits for participants. These were considered to be:

- To help structure infection control workshops that would be relevant and appropriate to the delegates.

- The questionnaire could also be useful as a demonstrable piece of evidence to authorities such as a primary care trusts (PCTs) that infection control requirements in relation to clinical governance were being addressed within a practice.

- The questionnaire could be used as a tool for a practice to undertake their own clinical audit project on infection control.

Each practice was asked to complete the questionnaires anonymously and return them to the Eastern deanery.

A total of 87 practices returned the questionnaires and the data collected was analysed to look for gaps in knowledge and practice procedures. Figures 2, 3 and 4 illustrate the results received for the sample questions from Figure 1.

\section{Design of the learning events - contents and delivery}

The decision on which topics to be included in the learning events was made by survey- ing the data from the questionnaires to look for areas where there was a strong indication that knowledge or skills were lacking. To illustrate this, if we consider the results from the questions relating to Hepatitis B immunisation - Figures 2, 3 and 4 - it was clear that although most clinical staff had received Hepatitis $B$ immunisation, many had not had their levels of Hepatitis B antibody checked and an even greater proportion had no written records for Hepatitis B immunisation held at the practice. Hence there was a good case for providing training in these areas within the workshops.

In order for delegates to gain the maximum benefit from a learning opportunity, it is useful, in addition to the content, to consider the way in which the event will be delivered. One way of doing this is by including a range of delivery styles that match the learning styles of a range of people. In their manual of learning styles, Honey and Mumford ${ }^{3}$ suggested that learning occurs as part of a cycle. Figure 5, with people learning by undertaking an activity, reflecting on what happened, concluding from the experience why what happened did occur and planning what to do next. They went on to propose that four distinct learning styles exist and that though people may favour one of these, often learning usually takes place through a combination of styles.

In order to maximise the potential for learning to occur in the EPIC initiative, the content and delivery style of the workshops were designed to appeal to these differing leaning styles.

Activists tend to learn best from having new experiences and activities. In order to address this, scenario type exercises were used within the workshops. The scenario used within the workshops to aid learning around Hepatitis B immunisation is shown in Figure 6. Reflectors learn best by having time to think things over and an opportunity for discussion with others. These needs were met by organising the delegates into groups and allowing time for them to work on the scenarios.
Fig. 4 Results for question 13: 'is there a written record of clinical staff immunisation for Hepatitis B held at the practice?

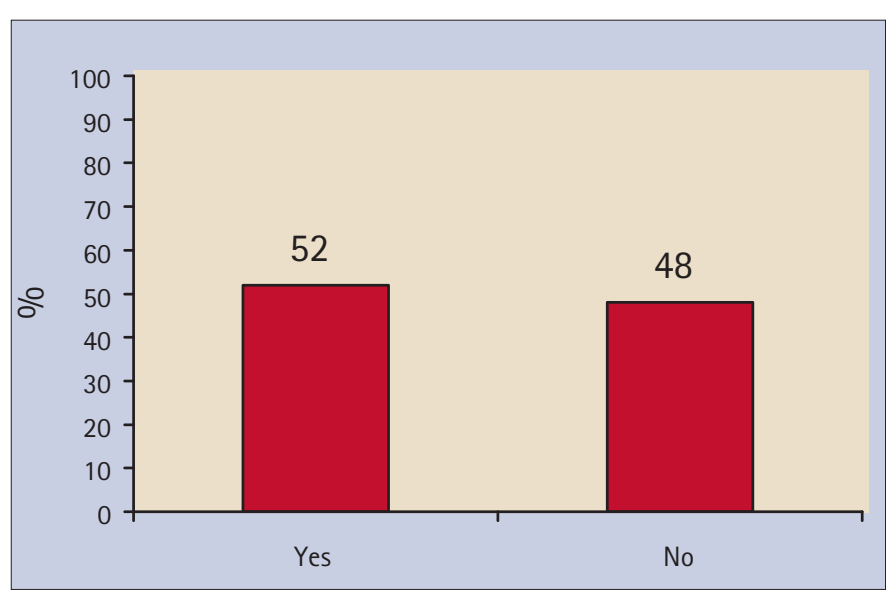


Fig. 5 The learning cycle (after Honey and Mumford).

Fig. 6 Hepatitis B scenario used for group work.

Theorists learn best from models and theories, needs catered for by including some didactic lecture type information, and situations where delegates had to think things through; some of the scenario work requiring the delegates to discuss what implications the exercises had for day to day practice.

Pragmatists can learn effectively by exercises relevant to their job. To address this, real life scenarios that could occur in practice situations were devised for use in the workshops. Pragmatists also learn by drawing up action plans for use at work. Information on what to include and how to design a practice infection control policy was included to help achieve this.

\section{Evaluation}

Course evaluation forms were completed by delegates at the end of each workshop. The

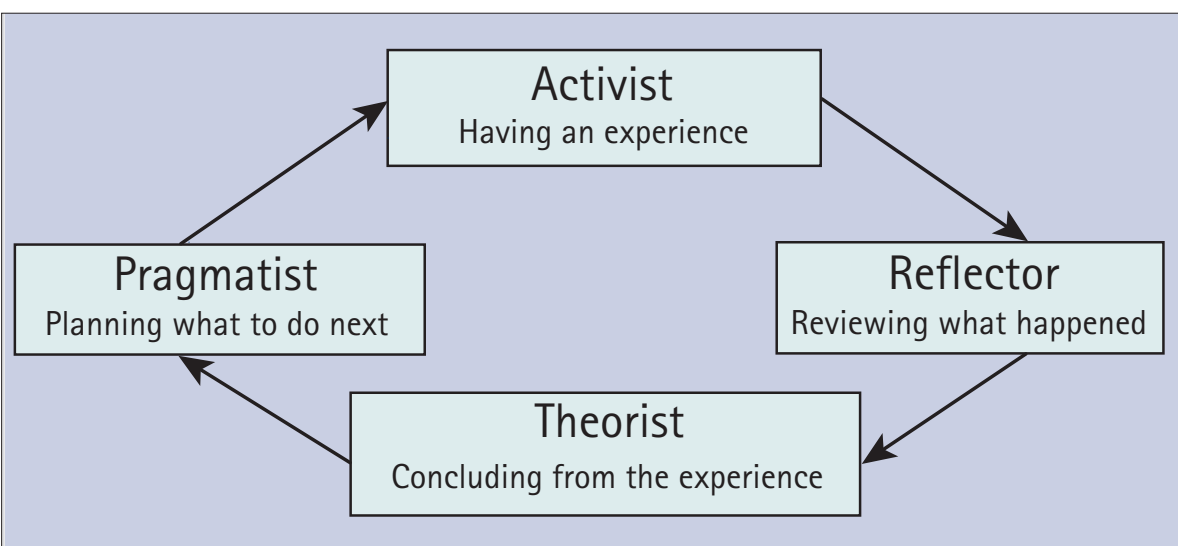

You are the senior partner in your practice. One of your colleagues is starting a family. One lunchtime he confesses to you that he is very worried about his wife and baby. On routine antenatal screening she has been found to be a Hepatitis B carrier.

The dentist is not worried that he might be infected as he had a full course of hep B vaccinations as a dental student. He believes he is immune.

What do you need to establish now?

Unfortunately there is no record of hep $B$ immunity - what should he do now?

evaluations for workshop delivery, content and professional relevance gave encouraging responses (Fig. 7). As well as requesting quantitative data, qualitative responses were also encouraged on the evaluation forms and comments such as 'Workgroup type activity makes the course extremely interesting and more challenging and relevant' were not uncommon.

Where more negative responses were given, these were acted upon by modifying the programme for the next delivery of the workshop. One response on an evaluation received read, 'The section on decontamination was tedious and the speaker lost her audience quickly'. This section of the programme was amended for the subsequent workshops so that although the same information was addressed it could be delivered in a more interactive way, with delegates working

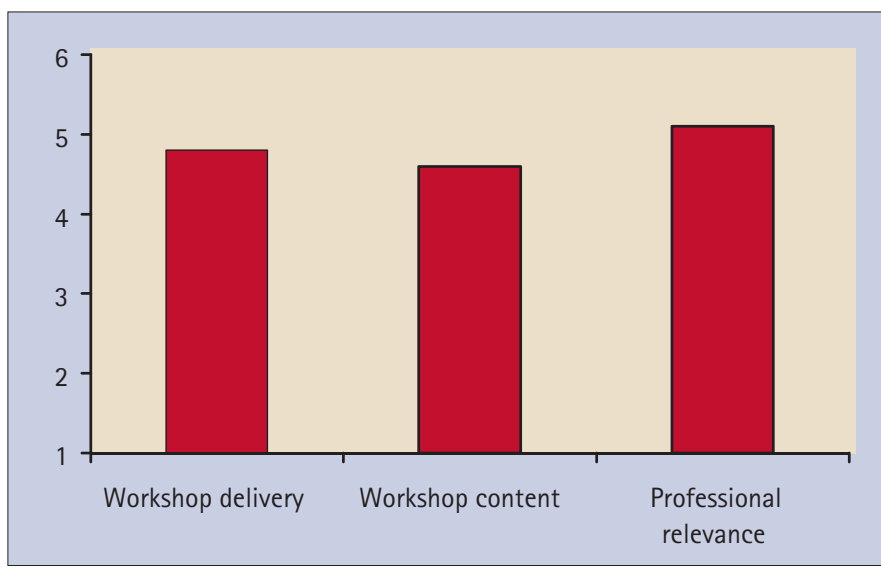

Fig. 7 Harlow course evaluation, mean scores $(1=$ poor, 6=highly favourable).
Testing shows that your colleague is a low risk carrier (hep B 'e' antibody + ve hep B 'e' antigen -ve) and has a viral load of less than 1000 per $\mathrm{ml}$.

What alterations to his practice should be made?

Testing shows your colleague is a high risk carrier (either hep B 'e' antigen and antibody not detectable or hep B 'e'antigen +ve antibody -ve)

\section{What should happen now?}

in groups to test their knowledge of the subject and the speaker facilitating feedback from the group work and providing answers and expanding on the topic as required.

\section{Conclusion}

The providers of postgraduate dental education including postgraduate dental deaneries have a duty to provide appropriate educational and training opportunities for dental practices, training needs analysis provides a valuable tool to help achieve this goal.

Equally important is the design and delivery of the training event itself. To maximise the potential learning experience, care must be exercised by course providers to ensure that a range of different learning styles are catered for.

Evaluation of learning events should be undertaken and where negative responses are received appropriate changes made to the event programme.

The author wishes to thank Sarah Brill, Infection Control Nurse at Essex Health Protection Agency for assistance in design and delivery of the initiative. Janet Heath, director of postgraduate dental education, Eastern deanery for her support for this initiative and Ann Smith, her personal assistant for distribution and collection of questionnaires.

1. General Dental Council. Lifelong learning. London 2001.

2. Grace M. Training needs analysis. Br Dent J 2001; 190: 524-526.

3. Honey P, Mumford A. The manual of learning styles. Maidenhead: Peter Honey, 1989. 